\title{
Informational needs related to aspirin prophylactic therapy amongst pregnant women at risk of preeclampsia - a qualitative study.
}

\author{
Raya Vinogradov ${ }^{1}$, Vikki Smith ${ }^{2}$, Stephen Robson ${ }^{3}$, and Vera Araujo-Soares ${ }^{4}$ \\ ${ }^{1}$ Newcastle Upon Tyne Hospitals NHS Foundation Trust \\ ${ }^{2}$ Northumbria University \\ ${ }^{3}$ Newcastle University Faculty of Medical Sciences \\ ${ }^{4}$ University of Twente Faculty of Behavioural Sciences
}

October 29, 2020

\begin{abstract}
Introduction Despite being key to reducing the occurrence of pre-eclampsia in high risk women, adherence to aspirin prophylaxis is low, reflecting multifactorial challenges faced by pregnant women. It is therefore important to understand the barriers and facilitators of aspirin adherence in pregnancy. This sub-analysis of a qualitative study conducted to better understand barriers and facilitators of aspirin adherence describes informational needs related to aspirin use in pregnancy. Methods Fourteen postnatal women from North-East of England, who declared various levels of non-adherence to aspirin $(0-5 / 7$ prescribed) were interviewed using The Theoretical Domains Framework as a guide. A thematic framework analysis of semi-structured interviews was used. Results Several sub-themes were identified within the "Knowledge" domain: a) Active vs passive approach, b) Partners seeking knowledge, c) Sources of information, d) Preferred format of information. Not all women actively seek information; some choose not to pursue it as they find thinking of hypothetical risks disturbing. Although partners seek information about risks and risk reduction strategies, they are often not included in conversations with health care professionals. When information is accessed women use a wide range of informational resources from scientific articles and national services (e.g. NHS) website to social media sources and word-of-mouth. Women admit that reading leaflets can be difficult, preferring to receive information in interactive ways. Conclusion New interactive and accessible informational resources are needed to engage pregnant women and their partners in aspirin prophylactic therapy.
\end{abstract}

\section{Hosted file}

ANA informational resources BJOG V1.1.pdf available at https://authorea.com/users/371402/ articles/489747-informational-needs-related-to-aspirin-prophylactic-therapy-amongstpregnant-women-at-risk-of-preeclampsia-a-qualitative-study

\section{Hosted file}

Figure 1 Recruitment (ANA info res).pdf available at https://authorea.com/users/371402/ articles/489747-informational-needs-related-to-aspirin-prophylactic-therapy-amongstpregnant-women-at-risk-of-preeclampsia-a-qualitative-study

\section{Hosted file}

Table 1 participants characteristics (ANA informational res).pdf available at https: //authorea.com/users/371402/articles/489747-informational-needs-related-to-aspirinprophylactic-therapy-amongst-pregnant-women-at-risk-of-preeclampsia-a-qualitative-study

\section{Hosted file}


Table 2 Themes (ANA Info res).pdf available at https://authorea.com/users/371402/articles/ 489747-informational-needs-related-to-aspirin-prophylactic-therapy-amongst-pregnantwomen-at-risk-of-preeclampsia-a-qualitative-study 